\title{
MATURAÇÃO DA UVA ‘BENITAKA’ CULTIVADA EM CLIMA SUBTROPICAL
}

Francisco José Domingues Neto, Silvia Regina Cunha, Adilson Pimentel Junior, Daniel Callili, Giulia Andrich, Marco Antonio Tecchio

Universidade Estadual Paulista - UNESP, Faculdade de Ciências Agronômicas, Botucatu, SP. E-mail: fjdominguesneto@hotmail.com

\section{RESUMO}

Tradicionais produtoras de uvas finas para mesa, as regiões de Pilar do Sul e São Miguel Arcanjo requerem estudos relacionados à evolução da maturação a fim de garantir a colheita de frutos que atendam as exigências de mercado. $O$ objetivo deste trabalho foi avaliar a maturação da uva 'Benitaka' cultivada em clima subtropical. O experimento foi realizado em um vinhedo comercial da uva 'Benitaka' enxertada no porta-enxerto 420-A, em sistema de condução do tipo pérgola, no sétimo ano de produção, localizado em Pilar do Sul, SP, Brasil (23 48' S, 47ㅇ 42' O e altitude de 689 m), no ciclo produtivo de 2014/15. A partir do início da maturação, aos 114 dias após a poda (DAP), realizou-se amostragem semanal das bagas para a determinação dos teores de sólidos solúveis (SS), pH, acidez titulável (AT), relação SS/AT e açúcares redutores (AR), se estendendo a amostragem de bagas até a colheita (156 DAP). A uva 'Benitaka' cultivada em região subtropical apresentou boas características físico-químicas aos 156 dias após a poda, com valores de SS de 15,99 @Brix, AT de 0,49\% de ácido tartárico, pH 3,73, relação SS/AT de 32,68 e AR de 14,10 $\%$.

Palavras-chave: colheita; uva fina para mesa; Vitis vinifera.

\section{MATURATION OF GRAPE ‘BENITAKA' CULTIVATED IN SUBTROPICAL CLIMATE}

\begin{abstract}
Producers traditional of the fines table grapes, the regions of Pilar do Sul and São Miguel Arcanjo require studies related to the evolution of maturation in order to guarantee the harvest of fruits that meet market requirements. The aim of this work was to evaluate the maturation of the grape 'Benitaka' grown in subtropical climate. The experiment was conducted in a commercial vineyard of the grape 'Benitaka' grafted on the rootstock 420-A, in a pergola-type conduction system, in the seventh year of production, located in Pilar do Sul, SP, Brazil (23 48 'S, 47 42 'W and altitude of $689 \mathrm{~m}$ ), in the production cycle of 2014/15. From the beginning of maturation, at 114 days after pruning (DAP), weekly sampling of berries was carried out to determine soluble solids (SS), $\mathrm{pH}$, titratable acidity (AT), relationship SS/AT and reducing sugars (RS), extending the sampling of berries until harvest (156 DAP). The grape 'Benitaka' cultivated in the subtropical region showed good physicochemical characteristics at 156 days after pruning, with SS values of 15.99 Brix, AT of $0.49 \%$ of tartaric acid, pH 3.73, relationship SS/AT of 32.68 and RS of $14.10 \%$.
\end{abstract}

Keywords: harvest; fine table grapes; Vitis vinifera.

\section{INTRODUÇÃO}

Localizados ao Sudoeste do Estado de São Paulo, os municípios de Pilar do Sul e São Miguel Arcanjo se destacam no cultivo de uvas finas destinadas ao consumo in natura. O Brasil é um país extenso em área e diversificado climaticamente, com isso as uvas apresentam grande variação dos atributos físicos e principalmente químicos das bagas, não sendo diferente para a evolução da maturação. O conhecimento da evolução da maturação em determinada região permite ao produtor estimar o índice tecnológico de colheita, evitando colher uma fruta imatura e sem coloração adequada, impedindo a desvalorização econômica do produto.

Dentre as cultivares de uva fina para mesa com semente, destaca-se a 'Itália' e suas 
mutações coloridas, 'Rubi', 'Benitaka' e 'Brasil'. A uva 'Benitaka' foi descoberta em 1988, pelos senhores Sadao e Riyoiti Takakura em Floraí, Paraná, sendo lançada em 1991 como uma cultivar de coloração rosada-escura, que a diferencia das demais mutações, mesmo quando imatura apresenta coloração rosada (SOUSA; MARTINS, 2002).

As uvas são frutas não climatéricas, não amadurecem após seu desligamento da planta, em função disso, a colheita deve ser feita quando o fruto apresentar o estádio ideal para o consumo, ou seja, apresentando aspectos ideais de coloração, aroma, textura e sabor (KADER, 1992; LIZANA, 1995). Tais informações são importantes para a comercialização de uvas para mesa, pois na negociação, os aspectos visuais são preconizados, como o tamanho das bagas e uniformidade na maturação (PADILLA, 2007).

A maturação da uva se inicia logo que as bagas começam a mudança de cor da casca e se estende até a colheita, período em que a uva amolece cada vez mais, pela perda de rigidez da parede celular, acumulando açúcares, principalmente glicose e frutose. A avaliação da maturação das uvas é de suma importância para poder determinar o ponto ideal de colheita, sendo que as condições de maturação variam de ciclo para ciclo, razão pela qual o seu acompanhamento deve se repetir ano a ano, além de fatores como genética, manejo e clima que também influenciam na composição química das uvas e na evolução da maturação. Teores de açúcares, acidez titulável, sólidos solúveis, pH e a relação sólidos solúveis e acidez titulável (índice de maturação) são os indicativos mais importantes na definição do grau de maturação das uvas, pois estão diretamente envolvidas no sabor da fruta (ANTONIOLLI; LIMA, 2008; MOTA et al., 2009).

Assim, objetivou-se com este trabalho avaliar a evolução da maturação da uva 'Benitaka' cultivada em região de clima subtropical.

\section{MATERIAL E MÉTODOS}

O experimento foi realizado no ciclo produtivo de $2014 / 15$, no município de Pilar do Sul - SP, situado a 23 48' S e 47은 $42^{\prime} \mathrm{O}$ e altitude de $689 \mathrm{~m}$, em vinhedo comercial com a videira 'Benitaka' enxertada no porta-enxerto ' $420-\mathrm{A}^{\prime}$. As videiras estavam espaçadas em $4 \times 2 \mathrm{~m}$, no sétimo ano de produção, conduzidas em sistema do tipo pérgola. $O$ solo da região foi classificado como Latossolo Vermelho Distroférrico (EMBRAPA, 1999) e o clima, segundo Köppen, como subtropical úmido, com precipitação pluvial anual média de $1.475 \mathrm{~mm}$ e temperatura média anual de $18 \stackrel{\circ}{\circ} \mathrm{C}$.

A evolução da maturação da uva 'Benitaka' foi determinada a partir do início do amolecimento das bagas (114 dias após a poda), com coletas realizadas semanalmente. Em cada videira foram selecionados cinco cachos, dos quais em cada dia de coleta, seis bagas por cacho foram coletadas para a realização das análises físico-químicas.

O delineamento experimental utilizado foi inteiramente casualizado, com dez repetições compostas por parcelas experimentais de duas plantas, sendo os tratamentos representados pelos dias de coleta das bagas, sendo aos 114 , $121,128,135,142,149$ e 156 dias após a poda (DAP).

As amostras foram acondicionadas em sacos plásticos, mantidas em condições refrigeradas (temperatura de $5^{\circ} \mathrm{C}$ ), sendo enviadas ao Laboratório de Pós-colheita de Frutas e Hortaliças do Departamento de Horticultura, pertencente à Unesp, Campus de Botucatu, SP, onde procederam-se as análises. As variáveis determinadas foram: teores de sólidos solúveis (SS), por refratometria direta, com uso de refratômetro digital de bancada marca Atago $0^{\circ}$, e os resultados expressos em ${ }^{\circ} \mathrm{Brix} ; \mathrm{O} \mathrm{pH}$ foi determinado utilizando pHmetro digital de bancada Micronal B-274; a acidez titulável (AT) foi determinada por titulação com solução padronizada de $\mathrm{NaOH}(0,1 \mathrm{~N})$ em titulador potenciométrico utilizando fenolftaleína como indicadora e o resultado expresso em porcentagem de ácido tartárico; mediante resultados dos teores de SS e AT, determinou-se a relação SS/AT; o teor de açúcares redutores (AR) foi determinado pelo método colorimétrico de Somogyi-Nelson com base em curva analítica de glicose e as leituras realizadas a $535 \mathrm{~nm}$ e os resultados expressos em porcentagem (NELSON, 1944),

Os dados obtidos foram submetidos à análise de variância (Teste $F$ ) e análise de regressão polinomial em função dos dias após a poda.

\section{RESULTADOS E DISCUSSÃO}

Os teores de sólidos solúveis (SS) apresentaram aumento quadrático a partir do início da maturação até a colheita (Figura 1), com 
o valor máximo obtido de 15,99 @Brix, aos 156 dias após a poda (DAP). Domingues Neto et al. (2016) obtiveram para a uva 'Brasil' na mesma região em estudo, resultados similares, porém com valores inferiores de sólidos solúveis $(14,18$ oBrix). Salienta-se que, apesar da cultivar Brasil ser proveniente da mutação somática da cv. Benitaka, ambas uvas finas para mesa, há uma diversidade em suas características físicoquímicas, tornando-se necessária a avaliação da maturação de cada cultivar em região produtora.
O início da maturação é caracterizado por um baixo teor de açúcar nas bagas, consequência da utilização deste nos demais tecidos, principalmente para o desenvolvimento da planta e do fruto, bem como para o crescimento e maturação da semente. Já na fase de maturação, há uma modificação metabólica na utilização do açúcar, onde se tem rápido acúmulo deste na baga, conhecido como "véraison", e assim até atingir o patamar máximo (BLOUIN; GUIMBERTAU, 2004).

Figura 1. Evolução dos teores de sólidos solúveis do mosto da uva 'Benitaka' cultivada em região subtropical, Pilar do Sul-SP, 2016.

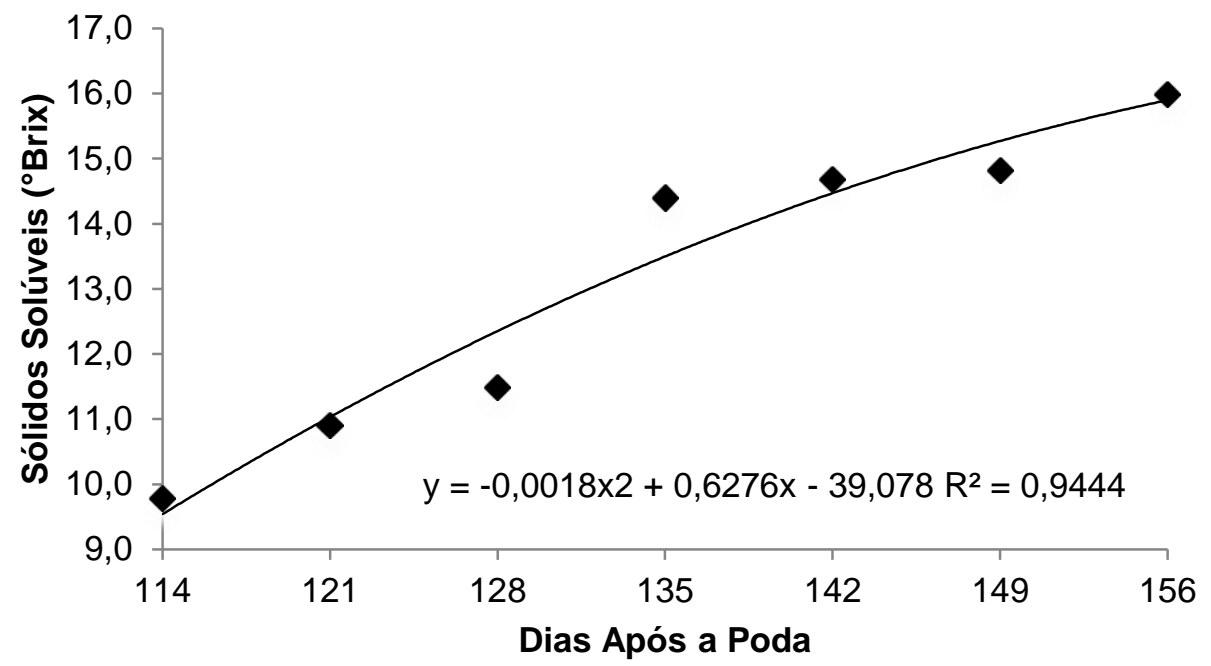

$\mathrm{Na}$ colheita, além de se levar em consideração o teor de SS, deve-se considerar ainda as condições climáticas do local e da variedade cultivada, uma vez que ataques de abelhas, pássaros ou até mesmo as doenças fúngicas e podridões do cacho causadas por excesso de umidade impeçam de que o fruto chegue ao teor de SS ideal. Também deve-se considerar outros atributos físico-químicos como - pH, acidez titulável, relação sólidos solúveis/acidez titulável e açúcares redutores.
$\mathrm{O} \mathrm{pH}$ apresentou um aumento linear, passando de 2,97 no início da maturação para 3,73 na colheita (Figura 2), com incremento diário de 0,0152 unidades. $\mathrm{O}$ aumento do $\mathrm{pH}$ está relacionado à salinificação dos ácidos orgânicos e ao aumento do cátion potássio (MANFROI et al., 2004), por este motivo, com a relação inversa entre pH e AT, ocorre a diminuição da acidez com $o$ aumento do $\mathrm{pH}$. 
Figura 2. Evolução dos teores do pH do mosto da uva 'Benitaka' cultivada em região subtropical, Pilar do Sul-SP, 2016.

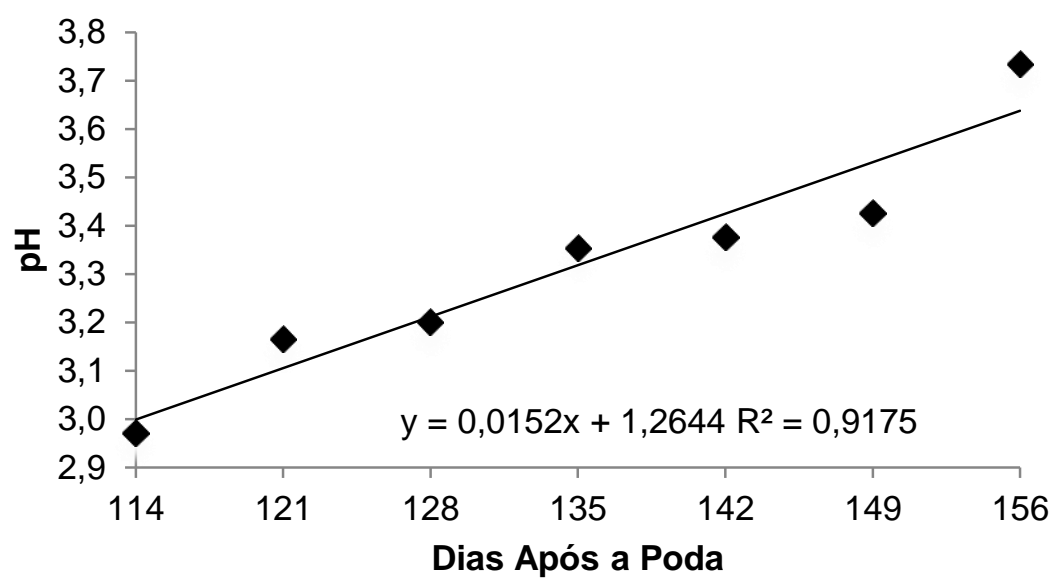

A acidez titulável (AT) apresentou redução quadrática em relação aos dias após a poda, com o ponto de mínimo $(0,48 \%$ de ácido tartárico) obtido aos 142 DAP (Figura 3). Resultados semelhante foram obtidos por Domingues Neto et al. (2016) para a uva 'Brasil'.

A AT aumenta da frutificação efetiva do fruto até o início da maturação e diminui desta fase até a fase de maturação da uva (RIBEREAUGAYON et al., 1986). A redução da acidez durante o processo de maturação se dá pela diluição do mosto com a entrada de água no fruto, transportada no xilema pela mobilização de bases que neutralizam os ácidos orgânicos e pelo processo respiratório. Além disso, o decréscimo da acidez titulável tem relação com a síntese dos principais ácidos da videira, que provém das folhas e bagas ainda verdes, ao passo que estes são sintetizados em menores quantidades com o início da maturação (MANFROI, 2003).

Figura 3. Evolução da acidez titulável do mosto da uva 'Benitaka' cultivada em região subtropical, Pilar do Sul-SP, 2016.

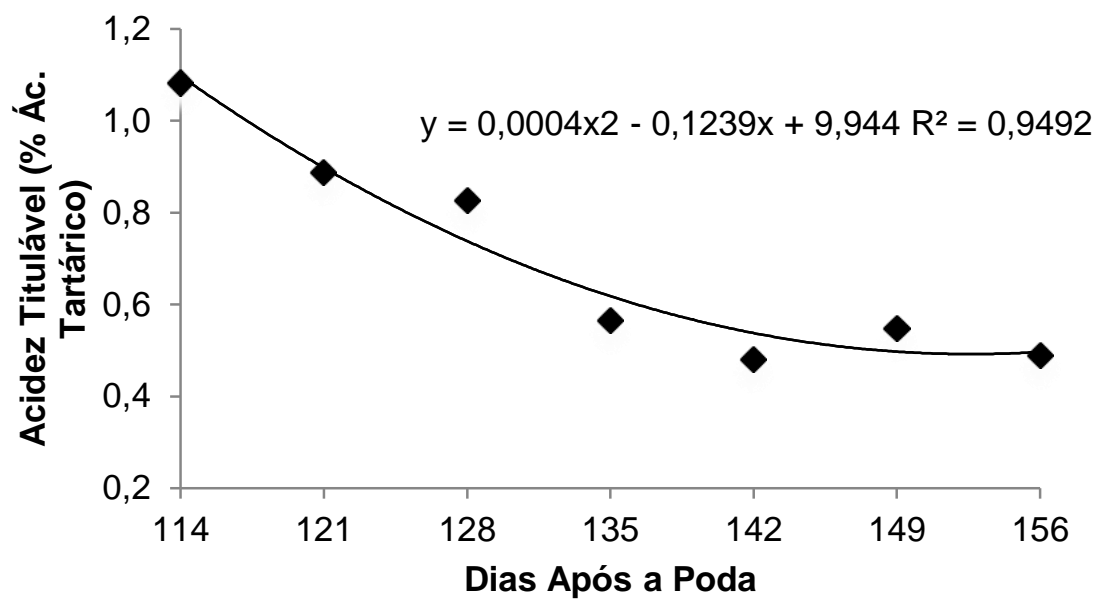

Houve aumento quadrático na relação SS/AT em função dos dias após a poda, com o valor máximo obtido aos 156 DAP (Figura 4). A relação SS/AT, denominada índice de maturação, representa o equilíbrio entre o teor de açúcares e ácidos, portanto quanto maior o valor dessa relação, o sabor da fruta será mais agradável. Assim, esta relação foi de 9,03 no início da maturação e 32,68 na colheita, indicando que a uva 'Benitaka' apresentava-se com sabor agradável (Figura 4). Os valores obtidos nesse estudo foram superiores aos encontrados por Domingues Neto et al. (2016) com a uva fina para mesa 'Brasil', na qual os autores obtiveram aos 156 DAP valores de 21,53 para essa relação, isso provavelmente se deve pela uva Brasil' ter 
apresentado valores de SS menores e de AT

maiores que em nosso estudo.

Figura 4. Evolução da relação sólidos solúveis/acidez titulável do mosto da uva 'Benitaka' cultivada em região subtropical, Pilar do Sul-SP, 2016.

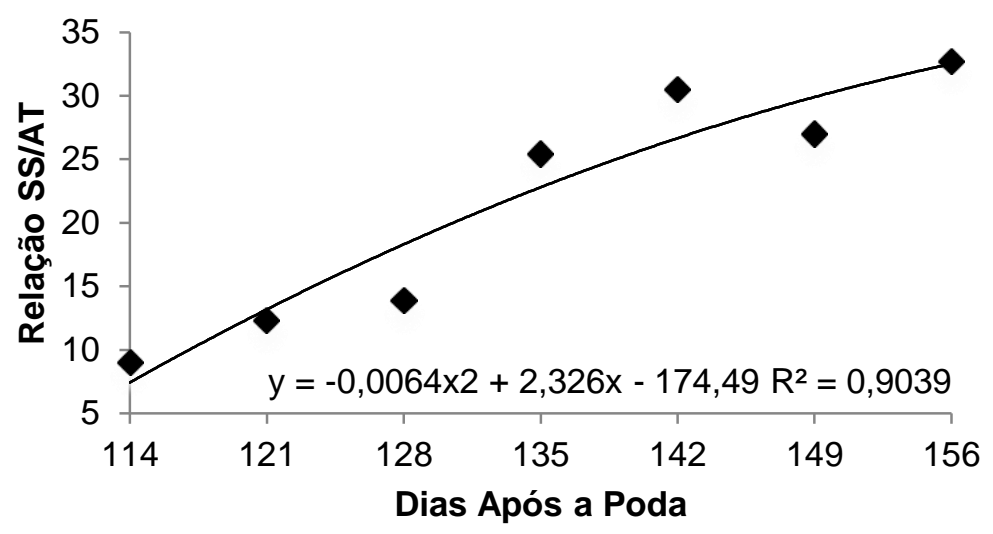

Os açúcares redutores (AR) apresentaram aumento quadrático em relação aos dias após a poda, com ponto de máximo da função aos 156 DAP (14,10\%). O açúcar é o constituinte que tem maior participação na densidade e no teor de sólidos solúveis (RIZZON; MIELE, 2006), isso foi verificado nesse trabalho, pois os valores de $A R$ acompanharam o crescimento dos teores de SS. Esse mesmo efeito foi encontrado por Domingues
Neto et al. (2016) com a uva 'Brasil', porém os valores foram superiores ao do presente estudo com a uva 'Benitaka', sabendo-se que os açúcares são os constituintes de maior participação no teor de SS, conclui-se que a uva 'Brasil' apresenta mais compostos que compões os SS que a uva 'Benitaka'.

Figura 5. Evolução dos açúcares redutores do mosto da uva 'Benitaka' cultivada em região subtropical, Pilar do Sul-SP, 2016.

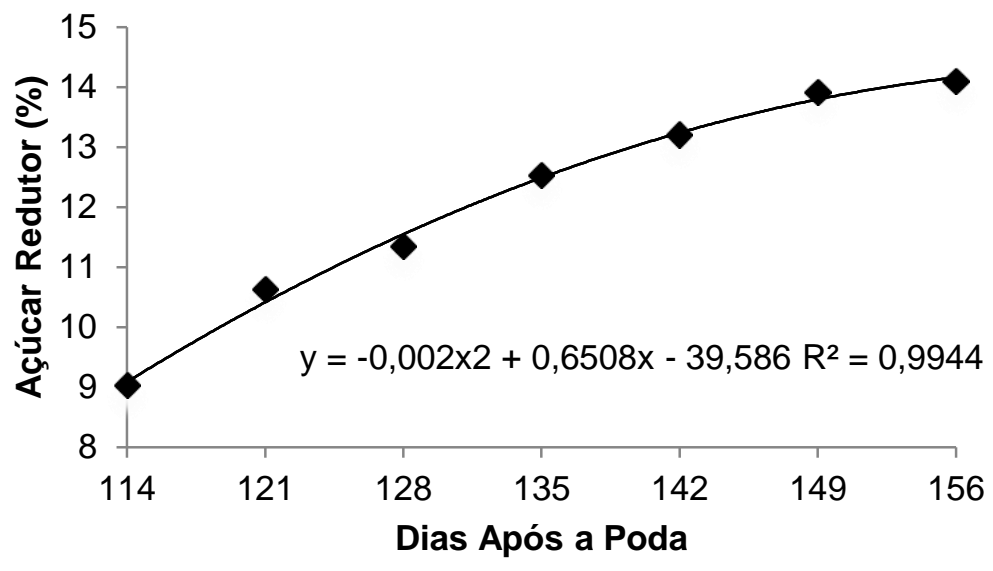

\section{CONCLUSÃO}

A uva 'Benitaka' cultivada em região subtropical, apresentou melhor qualidade físicoquímica aos 156 dias após a poda de produção.

\section{REFERÊNCIAS}

ANTONIOLLI, L.R.; LIMA, M.A.C. de. Boas práticas de fabricação e manejo na colheita e pós-colheita de uvas finas de mesa. Bento Gonçalves:
Embrapa Uva e Vinho, 2008.12p. (Circular Técnica, 77).

BLOUIN, J.; GUIMBERTEAU, G. Maduración ymadurez de la uva. Madrid: Mundi-Prensa, 2004.

DOMINGUES NETO, F.J.; PIMENTEL JUNIOR, A.; PAIVA, A P.M.; MODESTO, L.R.; CUNHA, S.R.; TECCHIO, M.A. Maturação da uva 'Brasil' na 
região sudeste de São Paulo. Revista Cultivando o Saber, v.9, n.3, p. 294-301, 2016.

EMBRAPA. Sistema Brasileiro de Classificação do solo. Brasília: EMBRAPA, Produção de Informação. Rio de Janeiro. EMBRAPA solo: 1999. $42 \mathrm{p}$.

KADER, A.A. (Ed.). Postharvest technology of horticultural crops. 2. ed. Oackland: Division of Agricultural and Natural Resources, University of California, 1992. 296p.

LIZANA, L.A. Algunos aspectos de cosecha y manejo de postcosechaen uva de mesa para exportacion. In: CEPOC. Manejo de uva de mesa para esportacion. Publicaciones Miscelaneas Agrícolas, Santiago, v.43, p. 35-43, 1995.

MANFROI, L.; MIELE, L.; RIZZON, L. A.; BARRADAS, C.I.N.; SOUZA, P.V.D. Evolução da maturação da uva Cabernet Franc conduzida no sistemalira aberta. Ciência Agrotecnica, Lavras, v.28, n.2, p.306-313, 2004.

MOTA, R.V.; SOUZA, C.R.; FAVERO, A.C.; CARVALHO, C.P.S.E.; CARMO, E.L.C.; FONSECA, A.R.; REGINA, M.A. Produtividade e composição físico-químicade bagas de cultivares de uva em distintos porta-enxertos. Pesquisa Agropecuária Brasileira, v.44, n.6, p. 576-582, 2009. https://doi.org/10.1590/S0100-

\section{X2009000600005}

NELSON, N.A. Photometric adaptation of the Somogyi method for the determination of glucose.The Journal of Biological Chemistry, Bethesda, v. 153, p. 375-380, 1944.

PADILLA, C. Consumer preference and willingness to pay for an officially certified quality label: implications for traditionalfood producers. Agricultura Técnica, v.67, n.3, p. 300-308, 2007. https://doi.org/10.4067/S0365-

\section{$\underline{28072007000300009}$}

RIBEREAU-GAYON, J.; PEYNAUD, É.; RIBÉ-REAUGAYON, P.; SUDRAUD, P. Carattere deivini, Maturazionedell'uva, Lieviti e batteri: trattatodiscienza e tecnicaenologica. Brescia: AEB, 1986.
SOUSA, J.S.I.; MARTINS F.P. Viticultura brasileira: principais variedades e suas características. Piracicaba: FEALQ, 2002. 368 p.

Recebido para publicação em 20/04/2017

Revisado em 30/11/2017

Aceito em 24/01/2018 